\section{Visión Electrónica Más que un estado sólido \\ https://doi.org/10.14483/issn.2248-4728}

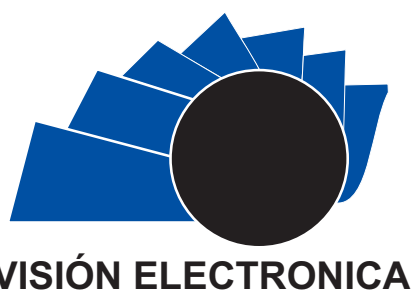

A Research Vision

UNIVERSIDAD DISTRITAL

FRANCISCO JOSÉ DE CALDAS

\title{
Human-robot scaffolding architecture
}

\author{
Arquitectura human-robot scaffolding
}

John Jairo Páez-Rodríguez', Enrique González-Guerrero ${ }^{2}$,

Andrea Sánchez-Vallejo ${ }^{3}$.

\section{INFORMACIÓN DEL ARTICULO}

Historia del articulo

Enviado: 28/11/2018

Recibido: 03/12/2018

Aceptado: 25/12/2018

\section{Keywords:}

Constructivism,

Flow Theory,

Human-Robot Interaction,

Scaffolding,

Social Robots.

\section{Palabras clave:}

Construccionismo,

Teoría psicológica del Fluir, Interacción Humano-Robot, Andamiaje,

Robots Sociales.

\section{ABSTRACT}

This study presents the advances in the design of the architecture called HumanRobot Scaffolding. The Architecture allows an anthropomorphic social robot to intervene assertively during the learning of the Mean-Fines analysis strategy. Its design recognizes three aspects. Firstly, the scaffolding educational strategy. Second, the psychological theory of Flow. Third, the paradigm BDI agents for the execution of the robot's goals. The partial validation of the architecture has been done with 20 children between 10 and 13 years old from two schools in Colombia. According to the results, the modules and the goals proposed in the architecture promote in an assertive way the learning of the Mean-Fines analysis strategy.

\section{RESUMEN}

El documento presenta los avances en el diseño de la arquitectura llamada HumanRobot Scaffolding. La arquitectura permite que un robot social antropomórfico intervenga de manera asertiva durante el aprendizaje de la estrategia de análisis de Medios-Fines. Su diseño reconoce tres aspectos. Primero, la estrategia educativa de andamiaje. Segundo, la teoría psicológica del Fluir. Tercero, el paradigma de agentes BDI para la ejecución de las metas del robot. La validación parcial de la arquitectura ha sido hecha con 20 niños entre 10 y 13 años de dos colegios en Colombia. De acuerdo a los resultados, los módulos y las metas propuestas en la arquitectura promueven de manera asertiva el aprendizaje de la estrategia de análisis de Medios-Fines.

\footnotetext{
BSc. In Technological Design, Universidad Pedagógica Nacional, Colombia. MSc. In Systems and Computation engineering, Pontificia Universidad Javeriana, Colombia. MSc. In Informational technologies applied to Education, Universidad Pedagógica Nacional, Colombia. Ph.D. (c) In Engineering, Pontificia Universidad Javeriana, Colombia. Current position: Professor at Universidad Distrital Francisco José de Caldas. E-mail: jjpaezr@udistrital.edu.co, johnpa@live.com. ORCID: https://orcid.org/ooo0-00032223-9883.

${ }^{2}$ BSc. In Electric Engineering, MSc. In Electric Engineering, Universidad de Los Andes, Colombia. D.E.A. In Robotics, Paris VI University. Ph.D. In Informatics, Evry University. Current position: Professor at Pontificia Universidad Javeriana, Colombia, Director of research group SIDRe in Systems Engineering. E-mail: egonzal@javeriana.edu.co. ORCID: https://orcid.org/0000-0001-8011-1760

${ }^{3}$ BSc. In Psicology, Universidad Santo Tomás, Colombia. MSc. In Education, Pontificia Universidad Javeriana, Colombia. Current position: Professor at Pontificia Universidad Javeriana, Colombia. E-mail: asanchezv@javeriana.edu.co, andresanchezvallejo@gmail.com. ORCID: https://orcid.org/oooo-0003-1921-8846.

Cite this article as: J. J. Páez-Rodríguez, E. González-Guerrero and A. Sánchez-Vallejo, "Human-Robot Scaffolding architecture", Visión electrónica, algo más que un estado sólido, vol. 1, no. 2, Special edition, july-december 2018. DOI revista: $\underline{\text { https://doi.org/10.14483/issn.2248-4728 }}$ 


\section{Introduction}

From the educative perspective, tools are used as representational systems to configure actions of thinking, to develop knowledge and to improve skills. Tools as Cuisenaire strips, Tower of Hanoi, abacus, and LEGO blocks are well known examples of representational systems. Nevertheless, there is an interest to use robots as educative tools because of their social, cognitive and emotional characteristics. Robots as mainstream authors can establish, support, change or conclude the cognitive and emotional relations that foster the learning process. These actions have been analysed by the scaffolding theory that was proposed by Jerome Bruner; it can be grouped into six functions: keep the attention, decrease the steps to solve the problem, keep the search in the target, highlight the difference between current and goal states, control the frustration and risk, and show an optimal way to solve the problem [1,2]. To implement the six scaffolding's functions is necessary to consider three aspects. First, to diagnose the cognitive and emotional aspects of the learner. Second, make interventions according to four strategies: direct instruction, guided instruction, cooperative work, and individualistic work. Third, to evaluate the learner's performance and the scaffolding process [3].

The aspects mentioned above has been considered to design and develop the Human-Robot Scaffolding architecture. Additionally, the design process is grounded in the BDI-agent theory. As a result, the architecture was implemented in the framework BDIBESA to implement BDI agents and was evaluated with the Baxter robot. Next, the details of the design, implementation and validation process are presented.

\section{Human-Robot Scaffolding Architecture}

The scenario of the implementation is composed by Baxter the robot, the learner, and the task.

Baxter is an anthropomorphic robot with handling capacity and emotional expression. Learners are children ranged between 10 and 13 years old. The task is a well-defined problem; the target is achieving a goal state through movements of blocks. For example, the Jumper game exchanges the position of two groups of blocks. Each group of blocks has the same color. To solve the problem there are two rules: the blocks can only move to the next empty space, and blocks can only jump two positions if the next position has a block with a different color. The objective is to solve the problem with the minimum amount of movements.

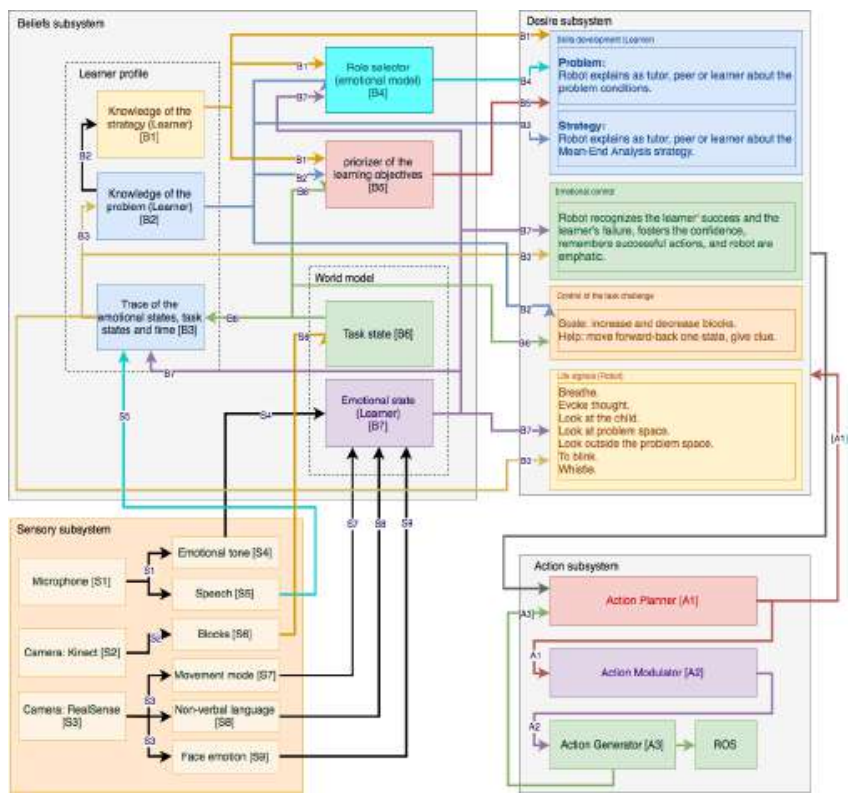

Figure 1. Human-Robot Scaffolding Architecture. Source: own.

Figure 2 shows the four modules of the human-robot scaffolding architecture: sensorial, beliefs, desires and intentions. The sensorial module recognizes three set of data. First, the emotional state of the learner. Second, a set of words spoken by the learner which are joined with the problem-solving process. Third, the block's position that represent the problem state. The beliefs module estimates three aspects: the operative knowledge of the problem, knowledge about of the Mean-End Analysis strategy, and the flow state of the learner based on the psychological flow theory [4]. The desire module defines, from a set of strategies, what strategy is the best to support the learning process. For instance, while the learner is thinking about the next step to solve the problem, the robot selects the action with the highest value to foster learning processes. The intentions module executes the action that was selected by the desire module. Figure 1 shows five set of actions to foster the learning of Means-End Analysis strategy: develop of skills, emotional control [5], and regulation of the problem challenge [6], give signs of live, and cognitive control [7]. For example, robot moves the arms, plays sounds, expresses phrases to encourage the learner, and moves the blocks.

\subsection{Sensorial Module.}

The sensorial module uses two types of ${ }_{i}^{n}$ sensors: deep camera and microphone. They are used to recognize the emotions, body language, problem state, and verbal judgements joined to the problem. 
The emotions are recognized in the module [S9] during changes of the problem state. The equation 1 describes an array $\left(\mathbf{M}_{e c}\right)$ to the facial expression as happy $\left(e_{1}\right)$, sad $\left(e_{2}\right)$, angry $\left(e_{3}\right)$, surprise $\left(e_{4}\right)$, fear $\left(e_{5}\right)$, disappointment $\left(e_{6}\right)$.

Equation 1: $\mathrm{M}_{e c}=\left[e_{1}, \ldots, e_{6}\right]$, where ${ }_{e i}=\sum_{=1} \mathrm{e}_{\mathrm{i}} /{ }_{n}$ nis the number of repetitions by change of state.

The facial movements are recognized in the module [S8]. The equation 2 describes an array $\left(\mathrm{M}_{e r}\right)$ with the value of the following movements from the face: encouraged $\left(f_{1}\right)$, look up $\left(f_{2}\right)$, keep the gaze to a specific point $\left(f_{3}\right)$, bit the lips $\left(f_{4}\right)$, close eyes $\left(f_{5}\right)$, turn the head $\left(f_{6}\right)$, wink the left eye $\left(f_{7}\right)$, wink the right eye $\left(f_{8}\right)$, and look down $\left(f_{9}\right)$.

Equation 2: $M_{e r}=\left[r_{1} \ldots, r_{9}\right]$ where; $r_{1}=\sum_{i=1}^{n} r_{i} /{ }_{n} \mathrm{n}$ is the number of repetitions by change of state.

In addition, six movements of the body were identified $[8,9,10,11]$. Rubbing hands $\left(p_{1}\right)$, stretching the $\operatorname{arms}\left(p_{2}\right)$, placing one hand on the chin $\left(p_{3}\right)$, placing one hand on the head $\left(p_{4}\right)$, placing both hands on his/her $\operatorname{head}\left(p_{5}\right)$, and raise $\operatorname{arms}\left(p_{6}\right)$.

Equation 3: $M_{p}=\left[p_{1}, \ldots, p_{6}\right]$, where; $p_{i}=\Sigma_{=1} p_{i} /{ }_{n} \mathrm{n}$ is the number of repetitions by change of state.

The data for each of the blocks used to solve the problem are grouped in the module [S6]. The arrangement of the blocks depends on the problem. For instance, the Jumper game has eight blocks sort vertically and the array description is $\left[\mathrm{R}_{0,0}, \mathrm{R}_{0,1}, \mathrm{R}_{0,2}, \mathrm{R}_{\mathrm{o}, \mathrm{s}}\right.$, $\left.\mathrm{B}_{0,0}, \mathrm{G}_{0,5}, \mathrm{G}_{0,6}, \mathrm{G}_{0,7}, \mathrm{G}_{0,8},\right]$.

The equation 4 describes the blocks position.

Equation 4: $M_{\text {blocks }}=\left[\begin{array}{ccc}S_{00} & \cdots & s_{0 n} \\ s_{m 0} & \cdots & \vdots \\ s_{m n}\end{array}\right]$ where; $\mathrm{m}=4, \mathrm{n}=8, \mathrm{~S}_{\mathrm{nm}}(\mathrm{R}, \mathrm{G}$, B, Y) and R, G, B, Y represent Red, Green, Blue, Yellow.

The blocks position allows estimating the operativeknowledge problem that is associated with how to how learner uses the problem operators, apply the rules, and knowledge about the initial state and goal state. The operative knowledge is used to estimate the Means-End Analysis strategy knowledge. It is calculated according to two learner's actions in every change of state: first, to identify different options and second, choose the best option to approach the goal.

\subsection{Beliefs module.}

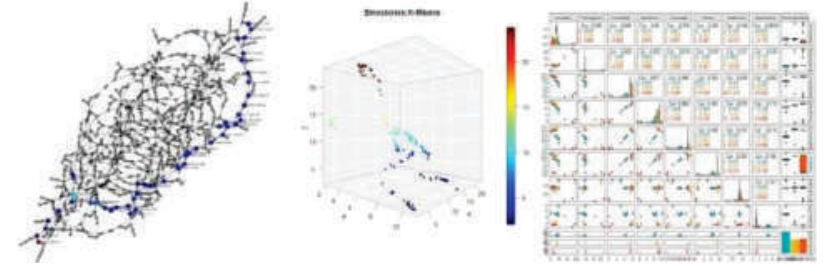

Figure 2. Learner's problem Space, Clusters k-Means (Anxiety, Flow, Boredom), SVM dimensions (Anxiety, Worry, Comfort, Confidence, Curiosity, Interest, Indifference, Boredom). Source: own.

Generally, the information from the sensors allows making a graph with the problem states visited by the learner. Figure 2 shows the space-problem for the Jumper game and the learner' states. The nodes are represented with the black color and the color of every node visited by the learner is associated with how many times the node was visited. For instance, blued nodes indicate the student's footprint during the problemsolving process; the range of colors between blue, yellow, green and red indicate the number of times each node was visited; being the least visited node blue and red the most visited node. As the equation 5 shows, the graph is used to merge the three datasets: the problem state, verbal judgements, and emotional states. Equation 5 [B3]: $G=(\mathrm{V}, \mathrm{E}), \mathrm{V} \rightarrow\left(n_{i}, e_{i}, t_{i^{-}, \mathrm{i}}, p\right)$ where $v$ :vertex, $E$ :edge, $n$ :node,e:emotion,t:time of the change of state.,p:words spoken by the learner.

The operational knowledge of the problem presented in the equation 6 , it is calculated by the number of trials, errors, and wins without considering what heuristic was used by the learner while the problem-solving process.

\section{Equation $6[\mathrm{~B} 2]: \mu=\sum$ trials $/ \sum$ hits}

On the other hand, equation 7 models the knowledge of the Mean-End analysis strategy. Aspects such as the percentage of the branch of the student, index of selection of the best options for each change of state of the problem, and time of planning and the presence of repetitive cycles. They are considered to estimate the two most relevant aspects during the use of the strategy of Media-Fines analysis: identify the options and select the best option in every change of state. In the human-robot scaffolding architecture, both aspects are estimated using a novel method named Cognitive Fuzzy Binary Maps. Next, the detailed information of the variables that make up the system is presented:

$$
\begin{aligned}
& \text { Equation } 7[\mathrm{~B} 1]: \delta=f(\alpha, \epsilon, \theta, \beta, \lambda, \vartheta) \\
& \text { Predicted options: }=\kappa=f(\phi, \sigma, \varphi, \lambda) \\
& \text { Select the best option: }
\end{aligned}
$$




\section{Where:}

Hits: $a=e_{i} \in £$ where; $£$ nodes of the problem

$e_{i}$, is the $i$-th node

- Mistakes: $\in=e_{i} \notin £$ where; $£$ nodes of the problem

$e_{i}$ space is the $i$-th node

-Ask for help: $\theta=1 \quad$ where $h$ indicates the help

requested from Baxter.

-Planning time: $\lambda=t_{e_{i}}-t_{e_{i-1}}$

- Depth planning: $\sigma=f\left(N_{\text {explored }} A_{\text {level }}\right)$ where

- $N=$ nodes,$A=$ adjacent.

-Learner repetitive cycles: $\phi=f\left(n_{i} \in N_{v}\right)^{\text {where }} n_{i}$ is the $i$-th node, $N_{v}$ set visited nodes.

- Learner corrects the last movement: $\beta=1$.

- Relevance of the action: $\vartheta=$ Evaluation $\rightarrow n_{i} \Rightarrow$ Posibilities $\rightarrow n_{i-}$

- Better continuous options:

$$
\varphi=\sum_{i=1}^{n=5} \vartheta_{i}
$$

Equation 8 represents the module [B4] that implements a fuzzy logic model to estimate the Emotional Control value, which is used together with the value of module [B1], to determine the robot role.

Equation $8[\mathrm{~B} 4]: \xi_{t, p, a}=f\left(e_{a}, \rho_{\alpha, \epsilon}, \sigma\right),(\delta)$

Where, $e_{a}$ is the learner's emotional state, $\rho_{\alpha, \epsilon}$ is the operational knowledge of the problem, $\sigma$ is the planning value by depth, $\delta$ are the learner' skills.

Additionally, the module [B5] contains; the rules of each of the problems (Jumper, stacking cubes, four horses), recursive function to generate the different problem-space, and Dijkstra function to evaluate the progress toward the target state in every change of state.

Equation $9[\mathrm{~B} 5]: D B=[G$, Dijkstra $]$

The values of the emotional state during the learning process were defined in three datasets: anxiety, flow, and boredom. For the construction of each dataset, thirty videos of children solving the problem was analyzed and the facial expressions and hands movements were categorized. Also, while an actor played to a learner solving the problem in the three different emotional states, the dataset was captured to train the SVM system. Table 1 presents seven of the twenty-two characteristics defined in [S8, S9] and the eight dimensions are joined with the learner's emotions.

\begin{tabular}{|l|c|c|c|c|c|c|c|c|}
\hline & Anxiety & Worry & Comfort & Confidence & Curiosity & Interest & Indifference & Boredom \\
\hline C1 & & & $\mathrm{X}$ & $\mathrm{X}$ & $\mathrm{X}$ & & & \\
\hline C2 & & & & $\mathrm{X}$ & & & & \\
\hline C3 & & & $\mathrm{X}$ & $\mathrm{X}$ & $\mathrm{X}$ & $\mathrm{X}$ & & $\mathrm{X}$ \\
\hline C4 & $\mathrm{X}$ & $\mathrm{x}$ & & & & & & \\
\hline C5 & $\mathrm{X}$ & & & & & & & \\
\hline C6 & $\mathrm{X}$ & & & & & & $\mathrm{x}$ & $\mathrm{X}$ \\
\hline C7 & & & $\mathrm{x}$ & $\mathrm{x}$ & $\mathrm{x}$ & $\mathrm{x}$ & & \\
\hline
\end{tabular}

Table 1. Example of the eight emotional dimensions and seven characteristics of hands movements.

Source: own.

Two methods have been tested; k-means and support vector machine. In both cases, the training was done with the twenty-two-data captured in [S8, S9] every 500 milliseconds while students were solving the problem. A dot product between the twenty-two-data and the eight dimensions was realized. In k-means three clusters are identified (anxiety, flow, and boredom). In SVM, the training data set were labelled with the actor's performance according to the three emotional-state mentioned.

\subsection{Intention Module}

The module was designed according to the BDI paradigm (Beliefs, Desires, Intentions) that considers the common sense and the intentional system of the human behavior. The BDI agent that supports the Human-Robot Scaffolding architecture is composed of the set of beliefs mentioned in the second module and represented in Figure 1 as $[\mathrm{B} 1, \mathrm{~B} 2, \mathrm{~B} 3, \mathrm{~B} 4, \mathrm{~B} 4, \mathrm{~B} 6, \mathrm{~B} 7$, B8]. Five sets of goals for the BDI agent were designed to develop the scaffolding process. They are based on the educational methodology of scaffolding, the psychological theory of flow and the theoretical foundations of meta-cognition. The sets are:

a) Development skills. It fosters the operational knowledge of the problem and the learning of Mean-End Analysis strategy [13].

b) Cognitive control. It stimulates three metacognitive processes: planning, supervision and evaluation.

c) Emotional control. It gives feedback about the solution of the problem, controls the frustration and acknowledges the successes of the learner [14].

d) Control of the challenge. It regulates the complexity of the task learning thought two actions: to change the number of blocks of the problem and change the problem.

e) Signs of life. It stimulates the recognition of the 
robot as a social agent while learning process.

The five sets have thirty-seven goals; each one is composed of an activation function and a contribution function. The first evaluates the viability of the thirtyseven goals. The second evaluates the contribution of the goal to the achievement of general objective of the agent.

Additionally, each goal has a plan associated. The execution of the plan involves the recognition of beliefs about the environment and the learner and use the robot as learning tool. For example, if the learner says: Baxter Help Me! then the goal "Give immediate assistant" is activated and the next plan is executed:

-Robot says: Let me help you!

-The current problem-state is saved.

-The best alternative to solve the problem is defined thought Dijkstra algorithm.

-Robot says: I will make the movement with the best alternative to approach the solution.

- Robot advances a state in the problem.

- Robot says: I finished, now you can continue.

\subsection{Action of the robot}

The architecture is being implemented in Baxter the robot (see figure 3). It has two arms, camera in each gripper, camera in the head, LCD screen, infrared sensors in gripper, ultrasonic sensor, kinaesthetic programming option, and force sensors. The communication between the robot and the BDI architecture is through ROS. The goals proposed in the BDI system combine the resources of the robot (screen, speakers, fans, lights, arms, grippers).

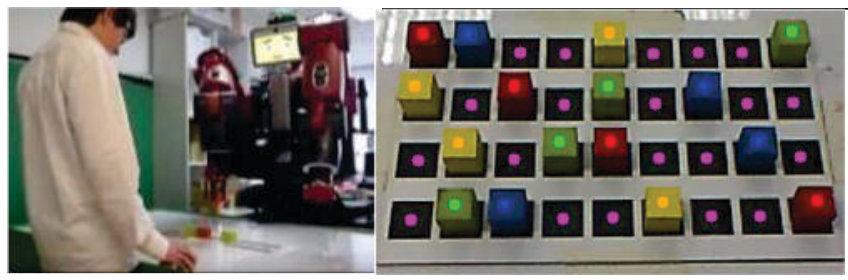

Figure 3. a) scenario of human-robot interaction. b) block recognition system. Source: own.

Figure 3a presents the interaction scenario of the apprentice with Baxter the robot. Figure $3 \mathrm{~b}$ presents the recognition conditions of the blocks. The architecture was developed in the BDI software development kit $[15,16,17]$. In BDI, the goals are divided into two groups: permanent and transitory. The selection of goals considers the beliefs related to the agent's awareness of the task and the level of commitment to the task. The behavior of the BDI agent is supported by three internal subagents: beliefs manager, objectives manager, and Mean-Ends manager. The first has four states: emergency, update, inference, and expiration. In addition, it poses five components: the world model, the skills and resources supervisor, the internal state of the agent, the emotional state, and the nature of the agent model. The second classifies the goals into four categories: identified, evaluated, activated, and eliminated. Also, it poses five goal priority levels: requirements, needs, opportunities, obligations, and survival. The priority of the objectives is evaluated to decide which of the goals must evolve and will become an intention. The agent's goals are arranged in a priority pyramid, where survival goals have the highest level. Finally, the Media-Ends manager, generates and executes a plan or selects a reactive action according to the intentions, beliefs, and available actions. This modular internal agent's model allows to easily implement it as a collection of parallel processes, where not only the three managers run concurrently but also the update of all the beliefs components and the evaluation of the whole set of agent's goals can be done simultaneously, leading to a real time and hybrid BDI agent implementation.

\section{Validation of the goals for cognitive and emotional support of the BDI agent.}

Next, the methodology for the goals'validation, emotional system and the actions of the learners are presented. In both cases, a single session was held with each of the children. To perform the goals 'validation a semantic analysis was used. It consists of interpreting the meaning and sense of communicative interactions between children and Baxter.

A synthetic transcription of the interactions during the educational intervention was made. It was divided in: framing of the researcher, Baxter's framework, initial state of the problem, development of the problem, new state of the problem, final state, and closure. The focus was the effectiveness of Baxter's intervention which had considered the feedback and the result in terms of the movement made by the child, solution of the problem, and correct strategy for the solution. All information was collected in the table 2 . 


\begin{tabular}{|c|c|c|c|c|c|c|c|c|c|c|c|c|c|c|c|c|c|c|c|c|}
\hline C & V & & C & & \multicolumn{7}{|c|}{ Child } & \multicolumn{5}{|c|}{ Robot } & $P$ & $\mathrm{~S}$ & $\mathrm{E}$ & $\mathrm{O}$ \\
\hline h & i & $\mathrm{i}$ & 0 & $\pi$ & $\mathrm{N}$ & $\mathrm{A}$ & $\mathrm{T}$ & 8 & $F$ & C & & & $M$ & & $F$ & & & C & $\begin{array}{l}f \\
f\end{array}$ & $t$ \\
\hline i & d & $\mathrm{m}$ & a & e & 0 & c & $y$ & & $\bar{m}$ & e & $t$ & V & $\begin{array}{l}\text { IVI } \\
0\end{array}$ & $\begin{array}{l}m \\
0\end{array}$ & 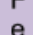 & O & 1 & a & $\begin{array}{l}e \\
c\end{array}$ & $h$ \\
\hline | & e & e & n & í & $\begin{array}{l}n \\
-\end{array}$ & $t$ & $\begin{array}{l}p \\
e\end{array}$ & $e$ & 0 & $n$ & e & r & & $t$ & e & $\mathrm{h}$ & 0 & $f$ & t & \\
\hline d & 0 & & t & c & V & i & 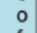 & 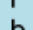 & $t$ & t & $r$ & b & e & 0 & d & e & & 0 & $\checkmark$ & 0 \\
\hline( & & & i & ${ }_{i}^{t}$ & $\begin{array}{l}e \\
r\end{array}$ & 0 & $f$ & D & i & $r$ & 0 & a & $\mathrm{m}$ & $\begin{array}{l}n \\
E\end{array}$ & $b$ & $r$ & & 1 & $n$ & b \\
\hline L & & & V & 0 & $\mathrm{~b}$ & 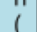 & e & , & 0 & 0 & b & 1 & $\mathrm{e}$ & s & a & b & $\mathrm{e}$ & d & $\begin{array}{l}\mathrm{e} \\
\mathrm{s}\end{array}$ & $\mathrm{S}$ \\
\hline e & & & $\mathrm{i}$ & d & \begin{tabular}{|l|}
$a$ \\
1
\end{tabular} & M & $\begin{array}{l}r \\
b\end{array}$ & $\mathrm{i}$ & $n$ & $f$ & $\mathrm{e}$ & i & $n$ & a & C & s & $\mathrm{m}$ & 1 & $\begin{array}{l}S \\
0\end{array}$ & $\mathrm{e}$ \\
\hline a & & & e & e & B & 0 & $\mathrm{a}$ & 7 & $a$ & $\mathrm{t}$ & $r$ & $z$ & & $\begin{array}{l}\mathrm{t} \\
\mathrm{e}\end{array}$ & $\mathrm{k}$ & e & S & $n$ & $\begin{array}{l}f \\
s\end{array}$ & r \\
\hline$r$ & & & S & $\begin{array}{l}\mathrm{s} \\
\mathrm{c}\end{array}$ & $\begin{array}{l}e \\
h\end{array}$ & $\begin{array}{l}v \\
e\end{array}$ & $\mathrm{i}$ & 2 & 1 & $t$ & v & a & & D & & $v$ & $t$ & a & $\begin{array}{l}\mathrm{c} \\
\mathrm{a}\end{array}$ & a \\
\hline $\mathrm{n}$ & & & t & i & $\begin{array}{l}n \\
a\end{array}$ & $\begin{array}{l}e \\
m\end{array}$ & z & a & S & e & $\begin{array}{l}a \\
t\end{array}$ & $t$ & & 10 & & a & a & C & $\begin{array}{l}f \\
f\end{array}$ & $\mathrm{t}$ \\
\hline e & & & a & p & v & $\mathrm{e}$ & $\begin{array}{l}a \\
t\end{array}$ & $\mathrm{i}$ & t & $\hat{t}^{2}$ & i & 1 & & p & & $t$ & $t$ & $t$ & ㅇ & i \\
\hline$r$ & & & $\mathrm{t}$ & ${ }_{i}^{t}$ & 0 & $\mathrm{n}$ & $\mathrm{i}$ & 0 & d & $i$ & 0 & $\begin{array}{l}0 \\
n\end{array}$ & & a & & 0 & e & $\begin{array}{l}1 \\
0\end{array}$ & d & O \\
\hline ) & & & e & $\begin{array}{l}\circ \\
n\end{array}$ & $r$ & ) & $\begin{array}{l}0 \\
\mathrm{n}\end{array}$ & $\mathrm{n}$ & $\mathrm{e}$ & $\begin{array}{l}0 \\
n\end{array}$ & $\mathrm{~s}$ & & & & & $\begin{array}{l}n \\
s\end{array}$ & & $n$ & $\begin{array}{l}\mathrm{n} \\
\mathrm{g}\end{array}$ & $\mathrm{s}$ \\
\hline
\end{tabular}

Table 2: Instrument for the semantic analysis of the human-robot scaffolding process. Source: own.

\section{Goals' validation.}

The "Wizard of Oz" strategy was implemented with a group of 8 students. After the semantic analysis and in concordance with the established goals; four types of intervention were observed: a) Cognitive support. b) Emotional support. c) Predominantly cognitive support, although also emotional. d) Predominantly emotional support, although also cognitive.

Also, the interventions were classified according to conditions: a) Timely, immediately after the child's execution-movement. b) Late, after the executionmovement of the child corresponding to the moment in which Baxter gives support. Due to the fast thinking of the learners, the robot's feedback could be correct or incorrect, this in relation to the execution-movement performed by learner. Although it is possible to say that $56.84 \%$ of the interventions were cognitive support and $92.85 \%$ of these were effective for the solution of the problem, they did not always allow the recognition of the correct strategy.

Baxter's cognitive interventions allowed to regulate and monitor the learning processes; especially the planning of movements. For instance, the execution and evaluation of the movements was recognized, especially by the child 6 .

Baxter's emotional interventions managed the attention of the children 6 on an aspect of the solution of the problem. This intervention allowed to maintain the interest in the search of the solution or strategy, and maintain perseverance in the task; it suggest that they contribute on the effectiveness of general intervention and validation of the goals. In $8.20 \%$ of the interventions, the reduction of the difficulty turned out to be a predominantly emotional intervention, although also cognitive. This type of intervention led children to states of frustration and in some cases decreased their interest by the task (child 4). However, they managed to positively alter the solution process in some cases (child 7 ) and in others, they stopped the process of comprehension ( $\operatorname{child} 2$ ).

Another characteristic observed on effective interventions is linked to feedback. It allows maintain the sequence of successes achieved by the learner and identify fragments of the strategy to solve the problem. For example, children 4, 6 and 7 leads to inference of the strategy. This intervention decreases impulsive actions and fosters the metacognitive activation to control of movement and plan the task.

The problem was solved by trial and error in $8 \%$ of the interventions. In these experiences, the effectiveness of the intervention was weak, to the extent that the children manage to solve the problem, but not to identify the correct strategy.

However, the effective and strong intervention requires a high cognitive regulation by learners (goal: cognitive control) since they are more attentive to the solving process than to the response to the movement. The intervention can diminish its effectiveness when the feedback made by Baxter is persistent in the error. For instance, in Baxter's interventions doing beep sound, saying "return to a previous correct state", "obviously, you just made an error", or "but before continuing, as well as to analyse what you should keep in mind to avoid repeat it ". These types of interventions should be reconsidered to give the chance to make better inferences of the correct movement by identifying the strategy or part of it. In cases in which children have low cognitive regulation, this situation makes it even more difficult to advance the solution of the problem, weakening the intervention.

As a matter of fact, timely interventions had a regulatory function by stopping wrong actions or encouraging successes. In some cases, Baxter's timely intervention allows the sense of movement to be recognized, but it does not necessarily make it possible for the learner to explore correct alternatives; it is as if the learner thought: "I know that movement is wrong, but I don't know what move to make." When this state is maintained, learners often give up trying to solve the problem ( $\operatorname{child} 2)$.

Moreover, $77.14 \%$ of interventions are timely and 
correct, offer reaffirmation to the planning and execution, which allows the identification of the strategy (child 5), so they can be considered effective. But, they depend on the strength of the processes of regulation of the learner, who finally selects and grants the role that the feedback will have on his performance.

Some interventions were characterized by delayed and erroneous feedback due to the complexity to control Baxter the robot with the Wizard of $\mathrm{Oz}$ strategy. Consequently, they obstructed the learner's performance and disoriented the process to solve the problem or the identification of the strategy, even if they have achieved part of the solution. This occurred when the learners were not sure of their response or had low regulatory processes that made it difficult for them to evaluate Baxter's intervention as erroneous.

According to these results, it is possible to validate the goals and conclude that the scaffolding strategy was effective. It allowed cognitive regulation to solve the problem. The feedback was important to the cognitive regulation and metacognitive activation. As a result, the proposed goals to the architecture are an assertive way to learn the Mean-End Analysis strategy.

Additionally, as result of the validation of the emotional system, the six basics emotion are not the best way to understand the emotional state while the learning process. When learners were solving the problem, there are a necessity to focus the attention on their cognitive and metacognitive process and the traditional expression are hidden. In fact, there are two times to show the emotions: while learners are thinking about how to tackle the problem and when they use arms to move the blocks to change the problem state.

Having said that, the body language to complement the facial expression was analysed. Body gestures expose the actions of thought in the problem-solving process. Characteristics such as body posture, facial expressions, eye movement and hand movement should be studied based on the degree of abstraction during the problemsolving process. To the design of the humanrobot scaffolding architecture, the study of gestures involved two aspects: recognition and emotional contribution according to flow theory. First, the recognition involves coding gestures according to the characteristics of the problem which was mentioned in the table 1 , and segmenting them according to their occurrence. Second, the twenty-two characteristics are useful to recognize the three emotional states joined to the learning process: anxiety, flow, and boredom.

As a conclusion, the Human-Robot Scaffolding Architecture develops a novel strategy to use tools in learning environments. If tools have better cognitive and emotional convergence with humans, they can implement strategies to give assertive support. The relation between the learner's emotional state, the task's challenge and effects of the robot's cognitive and emotional intervention are a topic of research that increases the possibilities of use of tools in educative proposes.

\section{References}

[1] D. Fisher and N. Frey, "Guided instruction: How to develop confident and successful learners", Chicago: ASCD, 2010.

[2] R. D. Pea, "The social and technological dimensions of scaffolding and related theoretical concepts for learning, education, and human activity", Journal of the learning sciences, vol. 13, no. 3, 2004, pp. 423-451. https://doi.org/10.1207/s15327809jls1303 6

[3] D. Wood, J. Bruner and G. Ross, "The role of tutoring in problem solving", Journal of child psychology and psychiatry, $\mathrm{v}$ o 1 . 17, no. 2, 1976, pp. $89 \ldots$ 100. https://doi.org/10.1111/j.14697610.1976.tbo0381.x.

[4] L. Harmat, F. Andersen, F. Ullén, J. Wright and G. Sadlo, "Flow Experience: Empirical Research and Applications", Springer, 2016. https://doi.org/10.1007/978-3-319-28634$\underline{1 .}$

[5] B. Kort and R. Reilly, "Analytical models of emotions, learning and relationships:

towards an affect-sensitive cognitive machine", Conference on virtual worlds and simulation, 2002.

[6] K. Chrysafiadi and M. Virvou, "Student Modeling for Personalized Education: A Review of the Literature", Advances in Personalized Web-Based Education, pp. 1-24. https://doi.org/10.1007/978-3-319-12895$\underline{5} 1$.

[7] B. Crandall, G. A. Klein and R. R. Hoffman, "Working minds: A practitioner's guide to cognitive task analysis", $\mathrm{M} \mathrm{i}$ Press, 20006 . https://doi.org/10.7551/mitpress/7304.0 $\underline{01.0001 .}$ 
[8] S. Goldin-Meadow, "Talking and thinking with our hands", Current Directions in Psychological Science, vol. 15, no. 1, 2006, pp. $34-39$ https://doi.org/10.1111/j.09637214.2006.0 0402.x.

[9] N. B. Brooks, D. Barner, M. Frank and S. Goldin-Meadow, "The Role of Gesture in Supporting Mental Representations: The Case of Mental Abacus Arithmetic", Cognitive Science, vol. 42, no. 2, 2017. https://doi.org/10.1111/cogs. 12527.

[10] M. W. Alibali, R. C. Spencer S. Kita and L. Knox, "Spontaneous gestures influence strategy choices in problem solving", Psychological Science, vol. 22, no. 9, 2011 , pp. 1138-1144. https://doi.org/10.1177/0956797611417722.

[11] M. Chu and S. Kita, "The nature of gestures' beneficial role in spatial problem solving", Journal of Experimental Psychology: General, vol. 140, no. 1, 2011 , pp. 102-116. https://doi.org/10.1037/a0021790.

[12] K. Charalampous and C. M. Kokkinos, "The Model of Interpersonal Teacher Behavior: a qualitative cross -cultural validation within the Greek elementary education context”, British Educational Research Journal, vol. 39, no. 1, 2013, p p. $182-205$. https://doi.org/10.1080/01411926.2011. $\underline{617437 .}$

[13] J. Sweller and M. Levine, "Effects of goal specificity on means-ends analysis and learning”, Journal of experimental psychology: Learning, memory, and cognition, vol. 8, no. 5, 1982 , pp. 463-474. https://doi.org/10.1037/02787393.8.5.463.

[14] J. E. Turner, R. Waugh, J. J. Summers and C. M. Grove, "Implementing high-quality educational reform efforts: An interpersonal circumplex model bridging social and personal aspects of teachers' motivation", Advances in teacher emotion research, 2009 , p p. 253-271. https://doi.org/10.1007/978-1-44190564-2 13.

[15] D. A. Crovo, "Interfaz RoboAct-pantalla multitáctil para interacción con el usuario en la creación de dramatizaciones de teatro robótico", thesis, Pontificia Universidad Javeriana, 2018.

[16] V. Parada and D. Steven, "Simulador basado en agentes inteligentes para el apoyo a la toma de decisiones en los planes operacionales de negocios en centros comerciales", thesis MSc., Pontificia Universidad Javeriana, 2017.

[17] M. A. Bermeo, D. S. Ávila, F. A. Merchán, E. González and A. M. González, "AIO robot: A EDI modular robotic dramatization platform", 18th International Conference on Advanced $\mathrm{R}$ o b o t i c s ( I C A R ), 20017 . https://doi.org/10.1109/ICAR.2017.8023528 